\title{
Papers
}

\section{The use of serodiagnosis in the retrospective investigation of a nursery outbreak associated with Escherichia coli $\mathrm{O} 157: \mathrm{H} 7$}

\author{
T Cheasty, R Robertson, H Chart, P Mannion, Q Syed, R Garvey, B Rowe
}

\begin{abstract}
Aims-To use serology to investigate an outbreak of verocytotoxin (VT) producing Escherichia coli 0157 in a hospital nursery, following the detection of faecal $E$ coli O157 (phage type 49) producing VT type 2. Methods-ELISA and immunoblotting techniques, based on lipopolysaccharide (LPS) purified from $E$ coli 0157 ; diagnostic bacteriology; serotyping and phage typing; DNA probes for VT.

Results-29 of 126 sera contained antibodies to the LPS of $E$ coli O157: 10 were from children, three were from staff, and 11 were from hospital kitchen staff. Five parents of children attending the nursery were antibody positive. Sixty four sera from other hospital staff and controls did not contain antibodies to the LPS of $E$ coli O157.

Conclusions-Serology detected evidence of infection with $E$ coli $\mathrm{O} 157$ in $23 \%$ of sera examined. By bacteriology alone, only a single case of infection with $E$ coli $O 157$ would have been detected. Serology is valuable in providing evidence of infection with $E$ coli 0157.

(F Clin Pathol 1998;51:498-501)
\end{abstract}

Keywords: Escherichia coli O157; serodiagnosis; outbreak

Strains of Escherichia coli producing verocytotoxin (VTEC), and particularly those belonging to serogroup O157, are a major cause of haemorrhagic colitis and the haemolyticuraemic syndrome in England and Wales as well as in other countries. ${ }^{1-3}$ Infection with $E$ coli $\mathrm{O} 157: \mathrm{H} 7$ is an important cause of kidney failure in infants and young children, and fatal cases occur among both the young and the elderly. ${ }^{4}$ The first confirmed outbreak of VTEC infection in the United Kingdom, caused by $E$ coli $\mathrm{O} 157$, was reported in $1983,{ }^{5}$ and since then the numbers of outbreaks and sporadic cases in England and Wales have increased. Between 1992 and 1994 there were 1266 bacteriologically confirmed infections caused by $E$ coli $\mathrm{O} 157$ and 18 outbreaks. ${ }^{6}$ In 1996 there were 660 confirmed infections with
E coli $\mathrm{O} 157$ and at least 10 outbreaks (Laboratory of Enteric Pathogens, unpublished data).

Infection with O157 VTEC is most commonly caused by the consumption of foods of bovine origin, predominantly ground (minced) beef and unpasteurised milk, although various other food vehicles including fermented meat products, unpasteurised apple juice, and raw vegetables have been reported..$^{7-9}$ Water borne outbreaks associated with both drinking and recreational water have also been described. ${ }^{10} 11$ Furthermore, there is evidence that infection can be acquired by person to person spread ${ }^{12}$ and by contact with farm animals. ${ }^{13} 14$

The isolation of $E$ coli $\mathrm{O} 157$ from a patient's stools identifies the cause of haemolyticuraemic syndrome or haemorrhagic colitis; however, in the absence of a culturable pathogen, particularly late on in the disease, an alternative method of providing evidence of infection is necessary. Infections with $E$ coli $\mathrm{O} 157$ result in the production of serum antibodies to the lipopolysaccharide (LPS) of this organism and a serodiagnostic test using the purified LPS of E coli O157 can provide evidence of infection. ${ }^{15-17}$ Initial characterisation of this immune response showed that it was an IgM rather than an IgG antibody response. ${ }^{15}$ Circulating antibody is detectable for at least 74 days after infection. ${ }^{17}$ We used this test to investigate a nursery outbreak of infection associated with E coli $\mathrm{O} 157$.

\section{The outbreak}

The outbreak occurred in a nursery which was attached to a hospital and provided care for the children belonging to the hospital staff. The nursery had 11 staff who looked after 31 children overall, with a maximum of 25 during any one period. All nursery meals were provided by the hospital kitchens. In October 1994 two of the children who attended the nursery developed the haemolytic-uraemic syndrome following an episode of bloody diarrhoea in the first case and diarrhoea in the second. The children were unrelated and their only link was attendance at the nursery. Both children were female, aged three years and two years. There was an interval of about two weeks between the two cases. $E$ coli O157 VTEC was 
Table 1 Results of screening for serum antibodies to the lipopolysaccharide of E coli 0157

\begin{tabular}{|c|c|c|c|c|c|c|}
\hline \multirow[b]{2}{*}{ Category } & \multirow{2}{*}{$\begin{array}{l}\text { At } \\
\text { risk }\end{array}$} & \multirow{2}{*}{$\begin{array}{l}\text { Number } \\
\text { tested }\end{array}$} & \multicolumn{2}{|l|}{ Diarrhoea } & \multicolumn{2}{|l|}{ No diarrhoea } \\
\hline & & & Seropositive & Seronegative & Seropositive & Seronegative \\
\hline Children & 31 & 24 & 9 & 6 & 1 & 8 \\
\hline Nursery staff & 11 & 11 & 3 & 2 & 0 & 6 \\
\hline Kitchen staff & & 22 & 0 & 0 & 11 & 11 \\
\hline Parents & & 5 & 1 & 0 & 4 & 0 \\
\hline Other hospital staff & & 40 & 0 & 0 & 0 & 40 \\
\hline Outpatients & & 24 & 0 & 0 & 0 & 24 \\
\hline TOTAL & & 126 & 13 & 8 & 16 & 89 \\
\hline
\end{tabular}

isolated from the faeces of the second case and a serum sample from the index case was positive for antibodies to $E$ coli O157 LPS. Based on these results an outbreak control team was formed. A case definition was produced, the nursery inspected, and an epidemiological investigation instigated. An outbreak questionnaire was issued and this revealed a further 13 children and five members of staff admitting to an episode of diarrhoea during the month of October (the period of probable transmission). Control measures were put in place and no further cases occurred. The duration of the outbreak was determined to be 28 days.

PATIENTS

A questionnaire concerning possible symptoms was sent to parents of nursery children and nursery staff. As the incubation period for infection with $E$ coli $\mathrm{O} 157$ may be up to 14 days and the date of onset for the first case was 14 October, symptoms were sought from 1 October. Those who replied that they had had an episode of diarrhoea (defined as two or more loose motions in a day) were requested to complete a more detailed questionnaire. The questionnaire inquiring about diarrhoeal symptoms was also sent to hospital kitchen staff.

Five members of the nursery staff and 15 children were reported to have had an episode of diarrhoea during the relevant time period associated with the two cases of haemolyticuraemic syndrome. None of the kitchen staff reported suffering from diarrhoea during this time. Faecal sampling was undertaken but the negative direct cultures prompted the outbreak team to consider serological testing of the staff and children.

Serum samples were obtained from 24 children attending the nursery, 15 of whom had diarrhoea; from five of their parents, one of whom had diarrhoea (these were the parents of the two haemolytic-uraemic syndrome cases and of two other children who had particularly severe diarrhoea); from 11 nursery staff, of whom five had diarrhoea; and from 22 kitchen staff, none of whom had diarrhoea. Sera from 40 other hospital staff and 24 sera from hospital outpatients unrelated to the outbreak were used to assess whether the infection had been more widespread in the hospital. These samples had been collected from hospital staff and patients for other laboratory tests during the outbreak period.

\section{Methods}

BACTERIOLOGY

Forty one faecal samples from children and nursery staff, irrespective of symptoms, were examined by routine bacterial culture for species of salmonella, shigella, campylobacter, and strains of $E$ coli $\mathrm{O} 157$. Faecal specimens were cultured for $E$ coli $\mathrm{O} 157$ on sorbitol MacConkey agar (SMAC), and incubated at $37^{\circ} \mathrm{C}$ for 24 hours (Oxoid; Unipath, Basingstoke, Hampshire, UK). Non-sorbitol fermenting colonies were selected and tested by slide agglutination using antibodies to $E$ coli $\mathrm{O} 157$ conjugated with latex particles (Oxoid O157 latex test, Unipath). Colonies agglutinated by the latex reagent were subcultured and identified as $E$ coli using the AP120E test (BioMerieux UK, Basingstoke, Hampshire, UK) and confirmed as belonging to serogroup O157 by slide agglutination with an antiserum prepared to $E$ coli $\mathrm{O} 157$ (Laboratory of Microbial Reagents, Central Public Health Laboratory, Colindale, UK). Presumptive E coli O157 isolates were serotyped, phage typed, and examined for genes encoding verocytotoxin ${ }^{18-20}$ by the Laboratory of Enteric Pathogens, Central Public Health Laboratory, Colindale.

SEROLOGY

One hundred and twenty six sera were examined for antibodies to the LPS of $E$ coli O157 by enzyme linked immunosorbent assay (ELISA) and immunoblotting procedures. ${ }^{15-17}$ ELISA plates were coated with $0.6 \mu \mathrm{g}$ LPS and reacted with serum diluted $1 / 1000$ in phosphate buffered saline containing $0.5 \%$ Tween20. Antigen-antibody complexes were detected using alkaline phosphate conjugated goat antiserum to total human immunoglobulin (Sigma, Poole, Dorset, UK) and $p$-nitrophenol phosphate $(1 \mathrm{mg} / \mathrm{ml}$, Sigma $)$ in diethanolamine buffer. The intensity of the final yellow colour was read at $405 \mathrm{~nm}$.

\section{Results}

\section{BACTERIOLOGY}

From 41 faecal samples, $E$ coli O157:H7 belonging to phage type 49 and reacting with a gene probe to VT2 was isolated from one of the cases of haemolytic-uraemic syndrome. The remaining 40 faecal specimens were all culture negative for $E$ coli $\mathrm{O} 157$.

\section{SEROLOGY}

Twenty nine of the 126 sera (23\%) contained antibodies to the LPS of E coli O157 (table 1). Ten were from children, nine of whom had diarrhoea. Three were from nursery staff, all of whom had diarrhoea, and 11 were from hospital kitchen staff, none of whom had diarrhoea. All five sera from the childrens' parents contained antibodies to the LPS of $E$ coli $\mathrm{O} 157$; only one parent had reported diarrhoea. The remaining 64 sera from other hospital staff and outpatients - none of whom had diarrhoeawere all negative when tested for antibodies to the LPS of $E$ coli $\mathrm{O} 157$. 


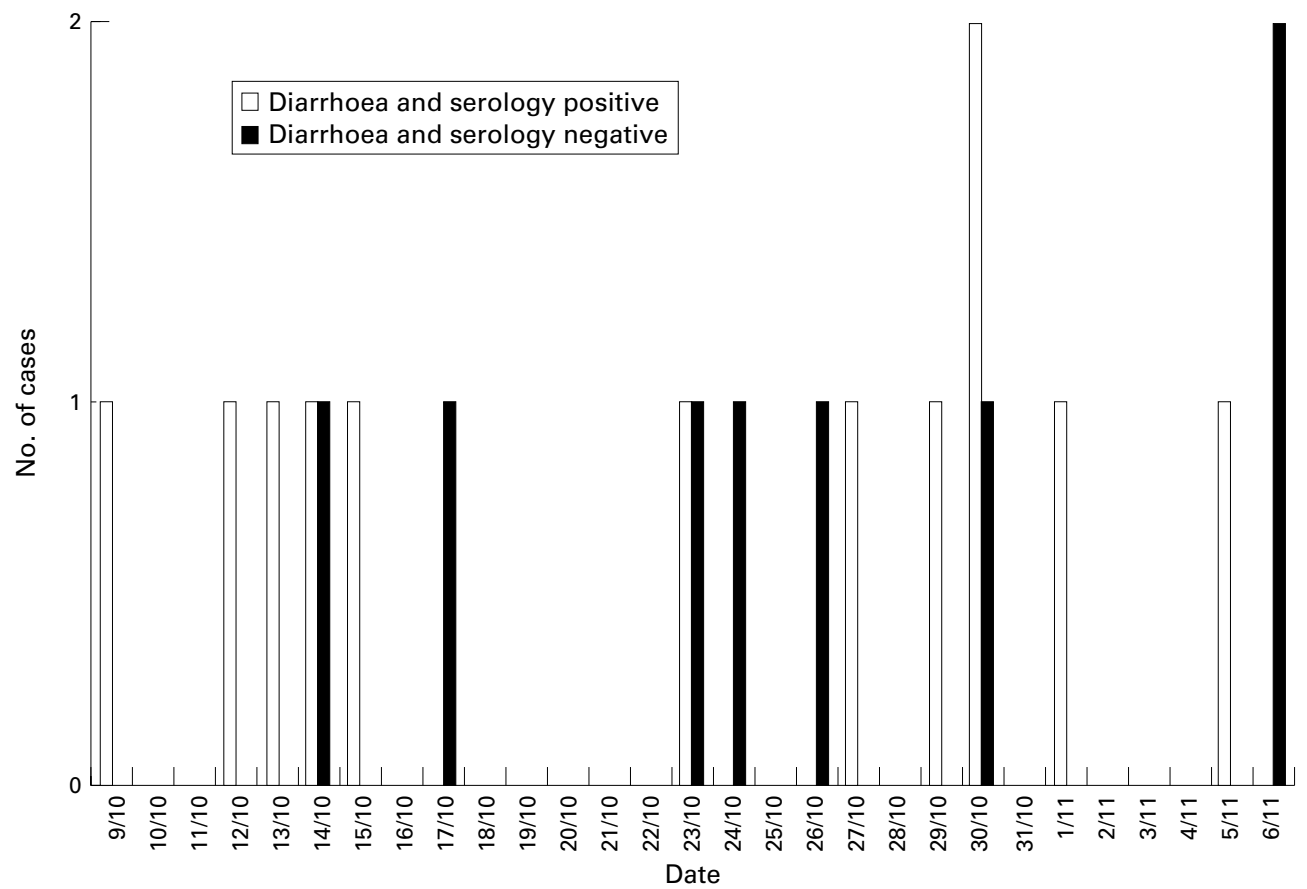

Figure 1 Outbreak curve.

\section{Discussion}

$E$ coli $\mathrm{O} 157$ was isolated from the faeces of one of the children with haemolytic-uraemic syndrome attending the hospital nursery; therefore by bacteriology alone evidence of infection would have been detected in only one patient. The failure to isolate $E$ coli $\mathrm{O} 157$ from the remaining children and staff of the nursery who were seropositive could be explained by the time delay between the two cases of haemolytic-uraemic syndrome and the recognition and investigation of an outbreak. Alternatively, those infected were no longer shedding faecal $E$ coli $\mathrm{O} 157$, or the numbers of bacteria excreted were too low to detect using SMAC. Possibly, the use of a more sensitive medium, for example cefixime-tellurite sorbitol MacConkey agar (CTSMAC) or enrichment culture, might have increased the sensitivity of detection. ${ }^{21}$

The negative results from the random testing of 40 sera obtained from hospital staff not connected with the nursery or kitchens and from 24 outpatients, and the absence of reports from the hospital of other cases of diarrhoea among hospital staff who ate hospital canteen food during this period, indicate that this outbreak was limited to the nursery. It is difficult to explain the large number of kitchen staff who were asymptomatic yet antibody positive. Such a high rate of seropositivity could be explained by the kitchen staff having previously been infected following handling of foodstuffs commonly associated with $E$ coli $\mathrm{O} 157$. The kitchen staff may well represent a distinct population within the hospital community and these results merit further study and investigation.

In relation to the outbreak investigation, a common source of infection or possible vehicle of infection was not recognised. The outbreak curve (fig 1) was, however, suggestive of person to person spread. The mildness of the diar- rhoeal illness among the staff and nursery children who did not have haemolytic-uraemic syndrome shows that not all cases of infection associated with $E$ coli $\mathrm{O} 157$ have prodromal symptoms of haemorrhagic colitis. The investigation highlighted problems that can occur in nurseries where cases of mild diarrhoea may not be notified by parents to nursery staff, and outbreaks may be missed or not recognised in time to allow early investigation and control. The nursery did operate an exclusion policy, but diarrhoeal symptoms occurring in children while away from the nursery would not be reported to the staff, preventing the minimal exclusion recommended by PHLS guidelines for diarrhoeal disease and the more stringent exclusion of two negative stools for cases of $E$ coli $\mathrm{O} 157 .^{22}$ As part of the outbreak investigation a telephone survey of nurseries randomly selected from the local telephone directory showed that although some form of exclusion policy existed no reference was made to recent symptoms occurring while away from the nursery, for example at weekends (Syed Q, unpublished data). This investigation proved the value of a serological test for obtaining evidence of infection with $E$ coli O157, and its potential for retrospective studies including those in which outbreak investigations are delayed.

1 Riley LW, Remis RS, Helgersom SD, et al. Hemorrhagic colitis associated with a rare Escherichia coli serotype. $N$ Engl f Med 1983;308:681-5.

2 Karmali MA, Steele BT, Petric M, et al. Sporadic cases of haemolytic-uraemic syndrome associated with faecal cytotoxin and cytotoxin-producing Escherichia coli in stools. Lancet 1983;i:619-20.

3 Kleanthous H, Smith HR, Scotland SM, et al. Haemolytic uraemic syndrome in the British Isles, 1985-8; association with verocytotoxin producing Escherichia coli. Part 2: Microbiological aspects. Arch Dis Child 1990;65:722-7.

4 Thomas A, Chart H, Cheasty T, et al. Vero cytotoxinproducing Escherichia coli, particularly serogroup O157, associated with human infections in the United Kingdom: 1989 to 1991. Epidemiol Infect 1993;110:591-660. 
5 Taylor CM, White RHR, Winterborn $\mathrm{MH}$, et al. Haemolytic-uraemic syndrome: clinical experience of an outbreak in the West Midlands. BMF 1986;292:1513-16.

6 Wall PG, McDonnell RJ, Adak GK, et al. General outbreaks of Vero cytotoxin producing Escherichia coli O157 in England and Wales from 1992-1994. Commun Dis Rep 1996;6: R26-33.

7 Tilden J, Young W, McNamara AM, et al. A new route of transmission for Escherichia coli: infection from dry fermented salami. Am f Public Health 1996;86:1142-45.

8 Besser RE, Lett SM, Weber T, et al. An outbreak of diarrhea and hemolytic uremic syndrome from Escherichia coli 2217-20.

9 Cieslak PR, Barrett TJ, Griffin PM. Escherichia coli O157:H7 infection from a manured garden. Lancet 1993;342:367.

10 Swerdlow DL, Woodruff BA, Brady RC, et al. A waterborne outbreak in Missouri of Escherichia coli O157:H7 outbreak in Missouri of Escherichia coli O157:H7 Med 1992;117:812-19.

11 Brewster DH, Brown MI, Robertson D, et al. An outbreak of Escherichia coli O157 associated with a children's paddling pool. Epidemiol Infect 1994;112:441-7.

12 Gross RJ. Vero cytotoxin-producing Escherichia coli O157. PHLS Microbiol Digest 1990;4:119-23.

13 Shukla R, Slack R, George A, et al. Escherichia coli O157 infection associated with a farm visitor centre. PHLS Commun Dis Rep 1995;5:R86-90.
14 Synge BA, Hopkins GF, Reilly WJ, et al. Possible link between cattle and $\mathrm{E}$ coli 0157 infection and a human. Vet between cattle and
Rec 1993;133:507.

15 Chart H, Scotland SM, Rowe B. Serum antibodies to Escherichia coli serotype O157:H7 in patients with hemolytic uremic syndrome. F Clin Microbiol 1989;27:285-90.

6 Chart H, Scotland SM, Smith HR, et al. Antibodies to Escherichia coli in patients with haemorrhagic colitis and haemolytic uraemic syndrome. F Clin Pathol 1989;42:973-6.

17 Chart H, Smith HR, Scotland SM, et al. Serological identification of Escherichia coli O157:H7 infection in haemolytic uraemic syndrome. Lancet 1991;337:138-40.

18 Gross RJ, Rowe B. Serotyping of Escherichia coli. In: Sussman M, ed. The virulence of Escherichia coli: reviews and methods. London: Academic Press, 1985:345-63.

19 Khakhria R, Duck D, Lior H. Extended phage-typing scheme for Escherichia coli O157:H7. Epidemiol Infect 1990;105:511-20.

20 Thomas A, Smith HR, Wilshaw GA, et al. Non-radioactively labelled polynucleotide and oligonucleotide DNA probes, for selectively detecting Escherichia coli strains producing
Vero cytotoxins VT1, VT2 and VT2 variant. Mol Cell Probes 1991;5:129-35.

21 Zadik PM, Chapman PA, Siddons CA. Use of tellurite for the selection of Vero cytotoxigenic Escherichia coli O157.f Med Microbiol 1993;39:155-8.

22 The prevention of human transmission of gastrointestinal infections, infestations, and bacterial intoxications. $C D R$ Rev 1995;5(11):R158-72. 